Marsha M. Cohen MSC MD MH SC FRCPC, Peter G. Duncan MD FRCPC, William D.B. Pope MD FRCPC, Christopher Wolkenstein MBBS FRCPC

\title{
A survey of 112,000 anaesthetics at one teaching hospital (1975-83)
}

This paper describes the outcome of a nine-year post-anaesthetic followup program in a large teaching hospital ( $N=112,721$ anaesthetics). Between time periods 1975-78 and 1979-83, more seriously ill patients (higher ASA physical status) were being treated. Anaesthetic practice also changed, with an increased use of balanced (multiple drug) anaesthetic procedures, a decrease in the use of halothane and an increase in the use of monitoring. Nonfatal anaesthetic complications intraoperative, recovery room and postoperative - were rare but there was an increase in the reported complication rate aver time. From 1975-78, 7.6 per cent of all cases had at least one intraoperative complication and from 1979-83, this rose to 10.6 per cent of all cases. For recovery room complications, there was an increase to 5.9 per cent in 1979-83 from 3.1 per cent in 1975-78. In time period 2 there was a 9.4 per cent chance of having a postoperative anaesthetic-related complication, and $a$ 0.45 per cent chance of a significant morbidity as a result. This represents an increase over time period I $(8.9$ and 0.40 per cent respectively). It is concluded that the anaesthetic experience, while associated with low mortality rates in recent years, is still associated with significant morbidity. It is conjectural at present whether this is reflective of preoperative patient status, anaesthetic practice, or other undefined variables associated with an operative experience.

\section{Key words}

RECORDS, ANAESTHESIA; STATISTICS; COMPLICATIONS.

From the Departments of Anaesthesia and Social and Preventive Medicine, University of Manitoba, Winnipeg. Address correspondence to: Dr. Marsha M. Cohen, Department of Social and Preventive Medicine, University of Manitoba, 750 Bannatyne Avenue, Winnipeg, Manitoba, R3E 0W3.

This research was supported by a grant from the Manitoba Health Research Council and a University of Manitoba Dean's Faculty Fund post-doctoral fellowship to Marsha M. Cohen.
Studies into the overall risk and quality of anaesthetic and surgical care have focused mainly on death rates after operative procedures. ${ }^{1-6}$ Few studies have examined the incidence of nonfatal complications, and few have examined the relationship between the preoperative condition of the patient, intraoperative factors, and eventual outcome. ${ }^{7}$ Large sample sizes are needed to assess anaesthetic and surgical outcomes because postoperative complications and deaths are relatively rare events. One large study by Lunn et al. ${ }^{8}$ reviewed over 150,000 anaesthetics administered to patients over a twenty-year period in Cardiff, Wales. They found that overall mortality rates fell from 1 in 35 anaesthetics administered in 1958 to 1 in 46 by 1977. However, they did not report nonfatal anaesthetic complications.

This paper presents the outcomes over a nine-year period from one large tertiary hospital serving a population of one million. Preoperative, intraoperative and postoperative variables were recorded in a systemic followup program initiated in 1975, and enabled an evaluation of anaesthetic and surgery related factors over time.

\section{Methods}

The Health Sciences Centre in Winnipeg is a 1,000-bed university affiliated teaching hospital with a separate Department of Anaesthesia since 1964. Since 1975, the Department of Anaesthesia has carried out a postanaesthetic followup program, which has been previously described in detail. ${ }^{9}$ In brief, for each anaesthetic administered to adult patients (obstetrics excluded), a check-off form has been completed by the attending anaesthetist. Information about ASA physical status, preoperative conditions, preoperative drug usage in the previous year, anaesthetic agents administered, anaesthetic technique used, duration of anaesthesia, 
monitors used, and intraoperative complications were recorded. With one exception, the variables and their definitions were the same throughout the study period. Recovery room complications were recorded by the recovery room nursing staff.

A specially trained nurse (the same individual throughout the study period) visited most long-stay patients and reviewed their charts. (It was not possible to visit day surgery or short-stay patients and therefore these are not included in the tabulations for postoperative complications.) If significant preoperative, intraoperative, or recovery room information was not entered by the anaesthetist, the nurse undertook to enter these variables for completion and accuracy of the record (thus minimizing anaesthetist bias). For patients interviewed, the nurse recorded any postoperative complications believed to be associated with anaesthesia which were unexpected, prolonged or unusual in nature. Defined criteria were used for each complication, and subjective symptomatology had to be voluntarily offered by the patient. Complications were judged to be major if they were considered a threat to the patient's life, prolonged the hospital stay or otherwise affected the outcome of the hospitalization. A complication was considered minor if it was in the nature of discomfort or inconvenience. The record was subsequently returned to the anaesthetist for a final review and his personal followup information. Since the anaesthetic record incorporated the billing sheet for the anaesthetic, the incentive to participate in the followup program was very high. A cross-check of the anaesthesia data base with the Manitoba Health Insurance Plan showed less than two per cent of cases were not recorded, and of these the majority were explanable by typographical errors in one of the files. Upon completion, the record was transferred for data processing. Previous to this study, monthly and yearly printouts had been produced which highlighted aberrations in protocol, complications or recording errors.

For the purpose of this study, reported complications were divided into three categories: intraoperative, recovery room and postoperative complications. As a validity check, a random sample of 100 charts from 1975 to 1983 was drawn, and the data on complications were confirmed by two experienced anaesthetists. The agreement between the anaesthetists was very high and therefore the computerized file was considered to be valid for purposes of this study. There was no difference in the validity between records from earlier or later years. There was no attempt made to definitively distinguish complications due to surgery from those due to anaesthesia. However, only complications of interest to anaesthetists (e.g., aspiration, hypotension and so forth) were recorded. For ease of presentation and to reflect changes over time, the data were grouped into two time periods 1975-78 and 1979-83. There were 52,197 anaesthetics administered in the first time period and 60,524 in the second. All data presented are based on the number of anaesthetics administered.

\section{Results}

The American Society of Anesthesiologists Physical Status Classification (ASA) of the patients is seen in Table I. The majority ( 80.9 per cent) of ASA 1 or 2 patients were elective, while the majority (56.1 per cent) of ASA 4 or 5 were emergencies. The proportions of patients rated in ASA categories 1 and 2 decreased over time with a corresponding increase in the proportion of patients classified as ASA 3 or more and in the emergency categories. While this may reflect a more accurate preoperative assessment by anaesthetists because of a more precise definition of ASA categories, it most likely reflects a trend towards the treatment of more seriously ill patients and the development of the institution as a tertiary referral hospital.

TABLE I Preoperative physical status

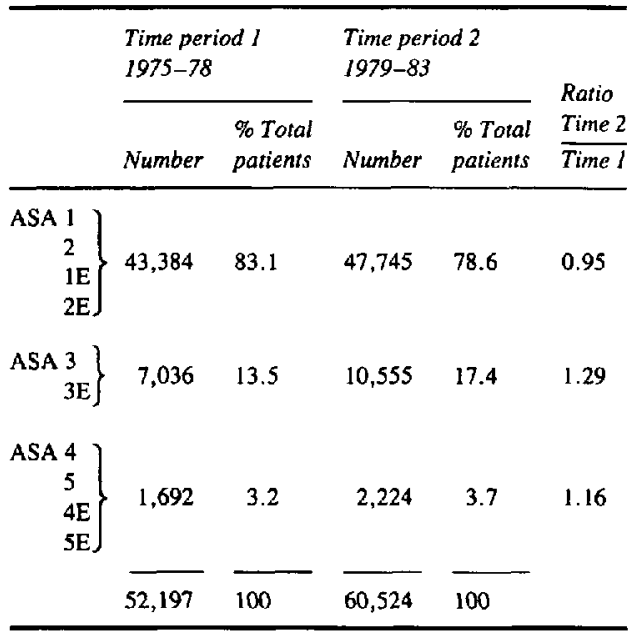


TABLE II Preoperative conditions

\begin{tabular}{|c|c|c|c|c|c|}
\hline & \multicolumn{2}{|c|}{$\begin{array}{l}\text { Time period I } \\
1975-78\end{array}$} & \multicolumn{2}{|c|}{$\begin{array}{l}\text { Time period } 2 \\
1979-83\end{array}$} & \multirow{2}{*}{$\begin{array}{l}\text { Ratio } \\
\text { Time } 2 \\
\text { Time I }\end{array}$} \\
\hline & Number & \% Total patients & Number & \% Total parients & \\
\hline Respiratory diseases & 8,835 & (16.9) & 11,337 & (18.7) & 1.11 \\
\hline Myocardial infarction & 1,723 & (3.3) & 2,433 & $(4.0)$ & 1.21 \\
\hline Other cardiovascular diseases & 9,898 & $(19.0)$ & 13,383 & $(22.0)$ & 1.16 \\
\hline Obesity & 5,102 & $(9.8)$ & 6,019 & $(9.9)$ & 1.01 \\
\hline Metabolic diseases & 4,127 & (7.9) & 5,166 & $(8.5)$ & 1.08 \\
\hline Renal diseases & 1,459 & (2.8) & 1,903 & (3.1) & 1.11 \\
\hline Preoperative drug usage & 5,792 & (11.1) & 7,356 & (12.1) & 1.09 \\
\hline Other conditions & 10,118 & $(19.4)$ & 11,809 & $(19.4)$ & 1.00 \\
\hline No preoperative condition & 26,642 & $(47.2)$ & 26,603 & $(43.8)$ & 0.93 \\
\hline One preoperative condition & 15,157 & $(29.0)$ & 14,050 & $(23.1)$ & 0.80 \\
\hline Two preoperative conditions & 7,584 & $(14.5)$ & 9,740 & $(16.0)$ & 1.10 \\
\hline Threc preoperative conditions & 4,814 & $(9.3)$ & 10,371 & (17.1) & 1.84 \\
\hline
\end{tabular}

Preoperative conditions among patients are seen in Table II. The most commonly seen were respiratory diseases (16.9 per cent of patients in 1975-78 and 18.7 per cent in 1979-83) and cardiovascular conditions (19.0 per cent in 1975 78 and 22.0 per cent in 1979-83). Cases with a preoperative myocardial infarction increased from 3.3 to 4.0 per cent of the total number of cases. The proportion of patients with preoperative conditions increased in the second time period from 52.8 to 56.2 per cent, but the types of conditions seen were not that different (the proportion of "other conditions" was the same). Overall, the proportion of patients with no preoperative conditions fell from 47.2 per cent in the first time period to 43.8 per cent in the second and the proportion of patients with two or more preoperative conditions increased from the first time period to the second. While these observations might reflect a reporting bias, the large number of participating anaesthetists ( 28 staff plus residents annually) and lack of incentive to augment patient assessments leaves such speculation unsupported. For example, the proportion of patients deemed "obese" was about the same in the two time periods, suggesting that the classification of these conditions was not substantially changed over time.

Approximately 12 per cent of patients acknowledged the use of medications during the year prior to surgery. Antihypertensives and diuretics were used in 5.8 and 5.7 per cent of the cases from the first time period and 8.1 and 7.4 per cent respectively in the second time period. (The exact type of drug was not recorded in the computer file.) The proportion of patients who had not used a preoperative drug decreased in the second time period from 62.5 to 60.1 per cent. The percentage of patients who used at least one drug in the previous year increased from 37 to 39 per cent in the second time period. However, the proportion using four or more drugs was the same ( 0.5 per cent).

The site of the surgical procedure (but not the specific procedure) was recorded and the tabulations can be found in Table III. Operative procedures in the perineal site (e.g., cystoscopy and $D \& C)$ were the most commonly performed and amounted to one quarter of all procedures in both time periods. The next most common site of operative procedures was intraabdominal (including such procedures as cholecystectomy, abdominal hysterectomy and so forth) (23 per cent in time period one and 20.9 per cent in time period two). Surgery on the extremities (about 16 per cent in both time periods) and on the "eye, ear, nose and throat" (about 14 per cent in both time periods) were the next most frequently performed. Surgery on the intrathoracic and major vascular sites showed the most marked increases over time (proportional increases of 44 and 71 per cent respectively), and was reflected in the increase in mean anaesthesia (operating) time from 157 minutes in time period one to 187 minutes in time period two. (Open heart procedures were reintroduced at this hospital in 
TABLE III Operative site

\begin{tabular}{|c|c|c|c|c|c|}
\hline & \multicolumn{2}{|c|}{$\begin{array}{l}\text { Time period } 1 \\
1975-78\end{array}$} & \multicolumn{2}{|c|}{$\begin{array}{l}\text { Time period } 2 \\
1979-83\end{array}$} & \multirow{2}{*}{$\begin{array}{l}\text { Ratio } \\
\text { Time 2 } \\
\text { Time } 1\end{array}$} \\
\hline & Number & \% Total patients & Number & $\%$ Total parients & \\
\hline Intracranial & 797 & (1.5) & 978 & (1.6) & 1.07 \\
\hline Eye, ear, nose, throat & 7,393 & $(14.2)$ & 8,142 & $(13.4)$ & 0.94 \\
\hline Dther head and neck & 2,463 & $(4.7)$ & 3,393 & (5.6) & 1.19 \\
\hline Intrathoracic & 474 & $(0.9)$ & 755 & (1.3) & 1.44 \\
\hline Major vascular & 721 & (1.4) & 1,443 & (2.4) & 1.71 \\
\hline Intraabdominal & 12,114 & (23.2) & 12,732 & (20.9) & 0.90 \\
\hline Trunk & 2,562 & (4.9) & 2,840 & $(4.7)$ & 0.96 \\
\hline Spine & 440 & $(0.8)$ & 557 & $(0.9)$ & 1.13 \\
\hline Perineal & 13,463 & $(25.8)$ & 15,656 & $(25.8)$ & 1.00 \\
\hline Extremities & 8,236 & (15.8) & 9,698 & $(16.0)$ & 1.01 \\
\hline Endoscopy & 3,087 & (5.9) & 4,726 & $(7.8)$ & 1.32 \\
\hline Other sites & 1,342 & (2.6) & 525 & $(0.8)$ & 0.31 \\
\hline Araesthesia therapy/diagnosis & 113 & $(0.2)$ & 191 & $(0.3)$ & 1.50 \\
\hline
\end{tabular}

1981.) Another change which reflected a trend in current medical practices was the increase in endoscopic procedures (proportional increase of 32 per cent).

There were some differences in anaesthetic technique between the two time periods. Inhalation anaesthesia with intubation was the most commonly used technique (about 46 per cent) followed by inhalation anaesthesia without intubation. Time period two saw the decline in the use of the pure narcotic technique and inhalation anaesthesia without intubation in favour of "balanced" (multi- ple drug) general anaesthetic procedures. Regional and local anaesthesia became more popular in the second time period, constituting 8.1 per cent of cases in the first period and 11.2 per cent in the second.

Table IV refers to anaesthetic agents used. Nitrous oxide remained the mainstay of general anaesthesia, being used in 90.1 per cent of procedures in the first time period and 86.1 per cent in the second. With regard to volatile anaesthetics, there was a shift from the use of halothane to enflurane in the second time period with halothane

TABLE IV Anaesthetic agents

\begin{tabular}{|c|c|c|c|c|c|}
\hline & \multicolumn{2}{|c|}{$\begin{array}{l}\text { Time period } 1 \\
1975-78\end{array}$} & \multicolumn{2}{|c|}{$\begin{array}{l}\text { Time period } 2 \\
1979-83\end{array}$} & \multirow{2}{*}{$\begin{array}{l}\text { Ratia } \\
\text { Time } 2 \\
\text { Time } 1\end{array}$} \\
\hline & Number & $\%$ Total patients & Number & $\%$ Total patients & \\
\hline Nitrous oxide & 47,042 & $(90.1)$ & 52,317 & $(86.1)$ & 0.96 \\
\hline Enflurane & 2,098 & (3.9) & 15,942 & (26.4) & 6.77 \\
\hline Halothane & 31,384 & $(60.2)$ & 22,947 & $(37.6)$ & 0.62 \\
\hline Barbiturates & 45,603 & $(87.4)$ & 48,582 & (79.9) & 0.91 \\
\hline Narcotic & 14,725 & (28.5) & 28,389 & $(46.7)$ & 1.64 \\
\hline Local & 3,895 & $(7.5)$ & 6,439 & $(10.6)$ & 1.41 \\
\hline Other agents & 4,773 & (9.1) & 13,455 & $(22.1)$ & 2.43 \\
\hline Relaxants for intubation only & 13,788 & (26.4) & 14,637 & $(24.1)$ & 0.91 \\
\hline Relaxants - ventilation & 17,909 & (34.3) & 21,854 & $(35.9)$ & 1.05 \\
\hline One agent & 2,557 & $(4,9)$ & 3,011 & $(5.0)$ & 1.02 \\
\hline Two agents & 3,847 & $(7.4)$ & 4,146 & $(6.8)$ & 0.92 \\
\hline Three agents & 14,412 & $(27.6)$ & 15,094 & $(24.8)$ & 0.90 \\
\hline Four + agents & 31,037 & (59.5) & 38,207 & (62.9) & 1.06 \\
\hline
\end{tabular}


TABLE V Monitor usage

\begin{tabular}{|c|c|c|c|c|c|}
\hline & \multicolumn{2}{|c|}{$\begin{array}{l}\text { Time period I } \\
1975-78\end{array}$} & \multicolumn{2}{|c|}{$\begin{array}{l}\text { Time period } 2 \\
1979-83\end{array}$} & \multirow{2}{*}{$\begin{array}{l}\text { Ratio } \\
\text { Time } 2 \\
\text { Time } 1\end{array}$} \\
\hline & Number & $\%$ Total patients & Number & $\%$ Total patients & \\
\hline Intra-arterial & 1,510 & (2.9) & 4,413 & (6.9) & 2.38 \\
\hline Central venous pressure & 402 & $(0.8)$ & 1,562 & (2.6) & 3.25 \\
\hline EKG & 44,855 & (85.9) & 58,925 & $(97.0)$ & 1.13 \\
\hline Precordial oesophageal & 1,028 & $(2.0)$ & 4,914 & $(8.2)$ & 4.10 \\
\hline Temperature & 1,695 & $(3.3)$ & 4,441 & $(7.4)$ & 2.24 \\
\hline Neuromuscular & 10,225 & (19.6) & 16,799 & $(27.7)$ & 1.41 \\
\hline Other monitors & 557 & $(1.1)$ & 7,310 & $(12.2)$ & 11.09 \\
\hline No monitors & 6,510 & $(12.5)$ & 1,759 & $(2.9)$ & 0.23 \\
\hline One monitor & 33,657 & $(64.5)$ & 36,069 & $(59.3)$ & 0.92 \\
\hline Two monitors & 9,091 & (17.4) & 14,205 & $(23.4)$ & 1.35 \\
\hline Three monitors & 1,482 & $(2.8)$ & 4,446 & $(7.3)$ & 2.61 \\
\hline Four + monitors & 917 & $(1.8)$ & 6,054 & $(10.0)$ & 5.56 \\
\hline
\end{tabular}

showing a proportional decline of about 40 per cent and enflurane a sixfold increase. Barbiturates also decreased in popularity over the nine-year period, used in 89 and 80 per cent of cases respectively. The use of narcotic agents and local anaesthetics showed large increases between the two time periods. The increase in the category "other agents" was mainly due to the introduction of isoflurane in 1981. The use of muscle relaxants increased over time reflecting the tendency towards increased use of balanced techniques in the second time period.

Table V shows the use of intraoperative monitors in the two time periods. Virtually all patients had an EKG monitor, and the proportion of anaesthetics administered with an EKG monitor varied from 86 per cent in time period one to 97 per cent in time period two. There was a trend towards the increased use of monitors as reflected in the increased percentage of cases where more than one monitor was used (87.5 per cent in time period one and 97.1 per cent in time period two). It is conjectural whether the increased monitoring reflects the changes in patient population over time, or simply heightened awareness by the anaesthetist of the role of monitoring in modern anaesthesia practice.

Complications encountered during the intraoperative period are seen in Table VI. All complications occurred at a low rate and therefore they are presented as the rate per 10,000 anaesthetics rather than as a percentage. Arrhythmias were the most frequently occurring intraoperative complication with a rate of 355.9 per 10,000 in time period one and 433.0 per 10,000 in time period two. Hypotension was the next most frequently encountered problem. Cardiac arrest occurred infrequently, at the rate of 6.1 per cent of 10,000 anaesthetics in 1975-78 and 7.8 per 10,000 in $1979-83$. Aspiration also occurred relatively infrequently (6.5 per 10,000 and 6.3 per 10,000 respectively). Hypertension, respiratory complications other than aspiration, and drug complications occurred much less frequently than arrhythmias or hypotension. Surgical complications were those complications due to a mishap in surgery which, in the judgement of the anaesthetist, affected the course of the anaesthetic. It is likely that these may be underreported. Overall the rates of intraoperative complications were reported as higher in the second time period as compared to the first by about two-fold. When viewed in association with the increased monitoring of patients and a change from intermittent to constant monitoring in later years, it is possible that this increased incidence of operating room complications represents increased recognition rather than an increased incidence per se.

Complications in patients while in the recovery room after surgery are presented in Table VII. With regard to complications due to anaesthesia and/or surgery, it was not uncommon for a complication occurring in the operating room to still be present while the patient was transferred to the recovery room. Therefore it is not possible to merely add 
TABLE VI Intraoperative complications

\begin{tabular}{|c|c|c|c|c|}
\hline & \multicolumn{2}{|c|}{$\begin{array}{l}\text { Time period } 1 \\
1975-78\end{array}$} & \multicolumn{2}{|c|}{$\begin{array}{l}\text { Time period } 2 \\
1979-83\end{array}$} \\
\hline & Number & $\begin{array}{l}\text { Rate per } 10,000 \\
\text { anaesthetics }\end{array}$ & Number & $\begin{array}{l}\text { Rate per } 10,000 \\
\text { anaesthetics }\end{array}$ \\
\hline Cardiac arrest & 32 & 6.1 & 47 & 7.8 \\
\hline Arrhythmias & 1,858 & 355.9 & 2,631 & 433.0 \\
\hline Hypotension & 1,098 & 210.0 & 1,971 & 324.4 \\
\hline Hypertension & 287 & 54.7 & 563 & 92.5 \\
\hline Aspiration & 34 & 6.5 & 38 & 6.3 \\
\hline Other respiratory & 387 & 74.0 & 720 & 119.0 \\
\hline Drug complications & 56 & 10.7 & 108 & 17.8 \\
\hline Surgical complications & 123 & 23.6 & 179 & 29.6 \\
\hline Other complications & 456 & 87.4 & 1,039 & 168.2 \\
\hline No complications & 48,243 & $9,242.5$ & 54,347 & $8,937.0$ \\
\hline One complication & 3,613 & 692.2 & 5,715 & 940.5 \\
\hline Two complications & 308 & 59.0 & 671 & 110.9 \\
\hline Three complications & 30 & 5.7 & 69 & 11.3 \\
\hline Fourt complications & 3 & 0.6 & 9 & 3.0 \\
\hline
\end{tabular}

Tables VI and VII to determine the total number of patients with complications (i.e., some individuals would be counted twice). Hypotensive incidents were the most prevalent complication during recovery (rate of 113 per 10,000 and 219 per 10,000 in the two time periods), while hypertensive episodes and arrhthymias were seen less frequently. Other complications occurred at very low rates. Except for cardiac arrests, the rate of all complications was higher in the second time period as compared to the first. The rate of cardiac arrest fell from 7.1 per 10,000 in the first time period to 3.5 per 10,000 in the second time period.

Table VIII shows the rate of postoperative com-

TABLE VII Recovery room complications

\begin{tabular}{|c|c|c|c|c|}
\hline & \multicolumn{2}{|c|}{$\begin{array}{l}\text { Time period } 1 \\
1975-78\end{array}$} & \multicolumn{2}{|c|}{$\begin{array}{l}\text { Time period } 2 \\
1979-83\end{array}$} \\
\hline & Number & $\begin{array}{l}\text { Rate per } 10,000 \\
\text { anaesthetics }\end{array}$ & Number & $\begin{array}{l}\text { Rate per } 10,000 \\
\text { ancesthetics }\end{array}$ \\
\hline Cardiac arrest & 37 & 7.1 & 21 & 3.5 \\
\hline Arrhythmias & 291 & 55.8 & 463 & 76.2 \\
\hline Hypotension & 590 & 113.0 & 1,328 & 218.6 \\
\hline Hypertension & 285 & 54.6 & 740 & 121.8 \\
\hline Aspiration & 9 & 1.7 & 20 & 3.3 \\
\hline Other respiratory & 198 & 38.0 & 535 & 88,0 \\
\hline Drug complications & 33 & 6.3 & 50 & 8.2 \\
\hline Surgical complications & 104 & 19.9 & 188 & 30.9 \\
\hline Other complications & 315 & 60.3 & 668 & 109.9 \\
\hline No complications & 50,563 & $9,687.0$ & 57,237 & $9,412.3$ \\
\hline One complication & 1,424 & 272.8 & 3,197 & 525.7 \\
\hline Two complications & 196 & 37.9 & 319 & 52.5 \\
\hline Three complications & 10 & 1.9 & 53 & 8.4 \\
\hline Four+ complications & 4 & 0.8 & 5 & 1.0 \\
\hline
\end{tabular}


TABLE VIII Postoperative complication rates in patients seen after surgery

\begin{tabular}{|c|c|c|c|c|}
\hline & \multicolumn{2}{|c|}{$\begin{array}{l}\text { Time period } 1 \\
1975-78, N=28,6.37\end{array}$} & \multicolumn{2}{|c|}{$\begin{array}{l}\text { Time period } 2 \\
1979-83, N=34,362\end{array}$} \\
\hline & Number & $\begin{array}{l}\text { Rale per } \\
10,000 \\
\text { anaesthetics }\end{array}$ & Number & $\begin{array}{l}\text { Rate per } \\
10,000 \\
\text { anaesthetics }\end{array}$ \\
\hline No postoperative complications & 26,003 & $9,080.2$ & 30,979 & $9,015.5$ \\
\hline Nausea and vomiting & 1,467 & 512.3 & 1,906 & 554.7 \\
\hline Sore throat & 432 & 150.9 & 478 & 139.1 \\
\hline Muscle soreness & 130 & 45.4 & 97 & 33.9 \\
\hline Headache & 119 & 41.6 & 126 & 44.0 \\
\hline Dental & 26 & 9.1 & 34 & 9.9 \\
\hline Mechanical & 148 & 51.7 & 146 & 42.5 \\
\hline Back pain & 21 & 7.3 & 48 & 13.9 \\
\hline Eye problem & 18 & 6.3 & 17 & 4.9 \\
\hline Upper airway & 12 & 4.2 & 2 & 0.6 \\
\hline Other respiratory & 30 & 10.5 & 33 & 9.6 \\
\hline Myocardial infarction & 11 & 3.8 & 47 & 13.7 \\
\hline Other cardiovascular & 169 & 59.0 & 197 & 57.3 \\
\hline Venous & 26 & 9.1 & 64 & 18.6 \\
\hline Arterial & 27 & 9.4 & 175 & 50.9 \\
\hline Nerve palsy & 12 & 4.2 & 6 & 1.8 \\
\hline Hepatitis & 6 & 2.1 & 2 & 0.6 \\
\hline Renal & 3 & 1.1 & 1 & 0.3 \\
\hline Urinary retention & 29 & 10.1 & 15 & 4.4 \\
\hline Psychiatric & 55 & 19.2 & 47 & 13.7 \\
\hline Awareness & 36 & 12.6 & 42 & 10.5 \\
\hline Other & 26 & 9.1 & 75 & 21.8 \\
\hline Postoperative minor & 2,556 & 892.6 & 3,235 & 941.5 \\
\hline Postoperative major & 116 & 40.6 & 153 & 44.5 \\
\hline One postoperative complication & 2,478 & 865.3 & 3,214 & 935.4 \\
\hline Two or more postoperative complications & 156 & 54.5 & 169 & 49.2 \\
\hline
\end{tabular}

plications among those patients who were visited after surgery by the anaesthesia followup nurse. Overall 28,637 patients ( 55 per cent of all anaesthetics) were visited in the first time period and 34,362 (57 per cent of all anaesthetics) in the second time period. In the first time period 91 per cent of patients had no postoperative complications while 90 per cent had no complications in the second time period. The overall rate of complications per 10,000 anaesthetics was 865 and 54.5 for one and two postoperative complications respectively in time period one and 935 and 49.2 for one and two postoperative complications respectively in the second time period. Of these complications, the rate of those judged to be minor in nature was 893 per 10,000 in the first time period and 942 in the second time period. The major complication rate per 10,000 anaesthetics increased from 41 in the first time period to 45 in the second.

As expected, nausea and vomiting (defined as greater than expected and requiring treatment) were the most frequently seen postoperative complication (rate per 10,000 was 512 and 555 in the two time periods). Sore throat (symptom volunteered by the patient) was the next most frequently seen. Postoperative myocardial infarction was seen in 11 patients in period one $(3.8$ per 10,000$)$ and 47 patients in period two (13.7 per 10,000). Other major complications such as hepatitis occurred infrequently. As with intraoperative and recovery room complications, postoperative complications occurred at a slightly higher rate in the second time period. However, minor complications such as muscle soreness, back pain and eye problems 
TABLE IX Anaesthetic complications summary

\begin{tabular}{|c|c|c|c|}
\hline & $\begin{array}{l}\text { Time period I } \\
1975-78 \\
\% \text { Total } \\
\text { anaesthetics }\end{array}$ & $\begin{array}{l}\text { Time period } 2 \\
1979-83 \\
\text { \% Total } \\
\text { anaesthetics }\end{array}$ & $\begin{array}{l}\text { Ratio } 195 \% \\
\text { confidence limits) } \\
\frac{\text { Time } 2}{\text { Time } 1}\end{array}$ \\
\hline Total intraoperative & 7.6 & 10.6 & $1.40(1.11,1.76)$ \\
\hline Total recovery room & 3.1 & 5.9 & $1.90(1.56,2.39)$ \\
\hline \multicolumn{4}{|l|}{ Postoperative } \\
\hline Major & 0.40 & 0.45 & $1.13(0.90,1.60)$ \\
\hline Minor & 8.9 & 9.4 & $1.06(0.94,1.08)$ \\
\hline \multicolumn{4}{|l|}{ Final tally* } \\
\hline only among patients seen & 25.5 & 31.6 & $1.24(1.21,1.26)$ \\
\hline among all patients & 14.0 & 17.8 & $1.27(1.24,1.30)$ \\
\hline
\end{tabular}

"Per cent of total number of anaesthetics in which there was at least one complication either intraoperative, in recovery room or postoperative.

occurred significantly less frequently in the second time period.

A final tabulation (Table IX) was undertaken to determine the proportion of patients undergoing anaesthesia and surgery who had suffered from at least one complication - whether intraoperative, recovery room or postoperative. There was a statistically significant increase between the two time periods for intraoperative, recovery room and overall complication rates ( $p<0.05$ ), but the small increase in postoperative major or minor complication rate was not statistically significant. In the first time period, considering only those patients seen by the postoperative nurse, 25.5 per cent of patients had at least one intraoperative, recovery room or postoperative complication. For the second time period, this increased to 31.6 per cent of all cases. If it is assumed that those patients not seen by the anaesthesia nurse had no complications (or else they would not have been allowed home), then the final tally of patients with operative and anaesthetic related complications was 14.0 per cent of all cases in the first period and 17.8 per cent in the second.

\section{Discussion}

Anaesthesia, like any scientifically based medical subspecialty, must base changes in its evolution on the most reliable information concerning the outcome of its efforts. Safety, efficacy and patient satisfaction must be the hallmarks of good anaesthetic care while ongoing monitoring of the success (or failure) in achieving these goals is imperative if professional and technological advances are to be made rationally. Unfortunately such monitoring is neither simple nor inexpensive. Many variables (patient status, surgical procedure, surgical expertise) make the delineation of anaesthesia-related factors obscure. The relative rarity of adverse outcomes makes it imperative to study large numbers of patients over time. Finally, the choice of multiple anaesthetic techniques and the individual physician performance makes generalizations difficult. Nevertheless, for both medical and legal reasons, the specialty of anaesthesia must continue to undertake surveillance, on both a local and national basis, of changes in patient outcomes as a consequence of anaesthetic "progress".

Previously published reports have evaluated the frequency of deaths "related to" anaesthetic procedures or anaesthetic mishaps that have resulted in medical-legal consequences. ${ }^{10}$ However, such information is difficult to extrapolate without data about the patient population, practice variables in each situation or the total anaesthetic experience of the surveyed community. In addition, while mortality or medical-legal tragedies may give valuable anecdotal information, the overall frequency of morbidity is unknown. A recent study from France included anaesthesia "accidents" as well as mortality. " However, differences in definition of outcomes makes it difficult to compare their series to this study. "Minor" complications, while seldom surveyed in reported series, may be discomforting enough to patients to justify changes 
in practice. The present study does attempt to present morbidity data obtained systematically over time. Mortality data is not included as the deaths due to anaesthetic complications were rare and tended to occur beyond the usual followup period.

The database presented here is subject to certain limitations in its ability to draw out preoperative patient variables and complications associated with surgery and anaesthesia. First, the data are compiled from a check-off form so that many variables are grouped together and are not very specific. Only those variables listed on the form are tabulated and additional variables of interest must be grouped together in the "other" category, thus potentially missing rare events. In addition, unless the check-off form is updated, changes of importance over time will not be recorded. Second, since the form is filled out by many different individuals, there will be variations in the opinions as to the inclusion or exclusion of some events (e.g., at what level of blood pressure is there significant hypotension?). However, since the same nurse has checked the form over the years, this problem has likely been overcome to some degree. Third, there is the possibility that adverse effects have been underreported. This has been minimized to some extent as the followup nurse reviews the patient's medical chart and records all complications even if the anaesthetist has not. Fourth, the nature of many of the variables is subjective, for example, ASA physical status. There may be changes over time or between physicians in the definition of ASA physical status or the criteria of application. This potential recording bias was minimized by examining all anaesthetics given by a large number of anaesthetists, and by subsequent review by the same followup nurse. Fifth, it is possible that the increase in complications seen was due to the increased use of continuous monitoring. However, it may be argued that continuous monitoring should avert adverse events. For example, should a small drop in blood pressure occur, action could then be taken and a significant hypotensive episode avoided. If intermittent monitoring had been used, then only large or persistent blood pressure drop would have been found. Thus, continuous monitoring should, ideally, show lower complication rates rather than higher ones.

There have been considerable changes over time with regard to anaesthesia and surgery as reflected in this databank. The anaesthetic techniques and agents have shown major shifts from $1975-78$ to 1979-83. Predominant in these changes is the replacement of halothane by enflurane, the use of balanced (multiple drug) techniques, and the increased use of regional anaesthesia. These changes may be due to the incorporation of information about adverse effects of some agents, improvements in technology, or decisions based on preoperative patient assessment. In addition, there have been changes in the types of operative procedures performed. This is reflected locally by an increase in intrathoracic, endoscopic and major vascular surgical procedures, changes which may also have affected anaesthetic practise.

In addition, the patient population also appears to have changed over these nine years. Several parameters taken together suggest that recently more patients have preexisting medical complications as reflected in the higher proportion of patients in higher ASA categories, the increasing number of patients with more preoperative conditions, and increasing numbers of preoperative drugs. It is not possible to distinguish whether the change in anaesthetic patient profile is due to the more seriously ill patients being treated, or whether newer techniques and monitoring have enabled more seriously ill patients to be considered for more complex surgery. Most likely a combination of these influences has occurred.

Overall the rates of immediate, intra- and postoperative complications are low, but not inconsequential (Table IX). In contrast to anaesthetic mortality, ${ }^{12}$ there are no large series with which to compare these results. Even if available, comparisons would be difficult due to differences in patient populations and surgical practice profiles. In this series, the rate of intraoperative and recovery room complications has increased from the first time period to the second despite the changes in anaesthetic techniques. Whether this can be explained by changes in patient population, improved anaesthetic vigilance and monitoring, or simply reporting practise cannot be determined from this study. However, that 17.8 per cent of all cases will experience some anaesthetic-related complication, and that almost ten per cent of patients will be either inconvenienced or suffer 
some morbidity as a result of the anaesthetic experience is a cause for continued concern.

\section{Acknowledgements}

The authors are indebted to the members of the Department of Anesthesia, Health Sciences Centre, Winnipeg especially D.B. Craig, M.D. and M. Burnham, R.N. Interpretations of the data are the authors' own and do not necessarily represent the official opinion of the Manitoba Health Research Council nor the Health Sciences Centre, Winnipeg. The helpful comments on earlier drafts of the manuscript by Noralou P. Roos, Ph.D. and the technical and secretarial expertise of Karen Hammarstrand, Carmen Steinbach and Bonnie Caldwell are acknowledged with thanks.

\section{References}

1 Marx GF, Mateo CV, Orkin LR. Computer analysis of postanesthetic deaths. Anesthesiology 1973; 39: 54-8.

2 Harrison GG. Death attributable to anaesthesia; a 10 year survey (1967-1976). Br J Anaesth 1978; 50: $1041-6$.

3 Hovi-Viander $M$. Death associated with anaesthesia in Finland. Br J Anaesth 1980; 52: 483-8.

4 Turnbull KW, Fancourt-Smith PF, Banting GC. Death within 48 hours of anaesthesia at the Vancouver General Hospital. Can Anaesth Soc J 1980; 27: $159-62$.

5 Farrow SC, Fowkes FGR, Lunn JN, Robertson IB, Samuel $P$. Epidemiology in Anaesthesia II. Factors affecting mortality in hospital. Br J Anaesth 1982; 54: 811-6.

6 Lunn JN. Hunter AR. Scott DB. Anaesthesia-related surgical mortality. Anaesthesia 1983; 83: 10906.

7 Owens WD, Spitznagel EL. "Anesthetic side effects and complications: an overview" in Anesthetic side effects and complications: seeking finding, and treating, Owens WD ed., International Anesthesiology Clinics 1980; 18: 1-10.

8 Lunn JN, Farrow SC, Fowkes FGR et al. Epidemiology in Anaesthesia I: Anaesthetic practice over 20 years. Br J Anaesth 1982; 54: 803-9.

9 Burnham M, Craig DB. A post-anaesthetic followup program. Can Anaesth Soc J 1980; 27: 164-8.

10 Utting JE, Gray TC, Shelley FC. Human misadven- ture in anaesthesia. Can Anaesth Soc J 1979; 26: 472-8.

11 Hatton F, Tiret $L$, Vourc'h $G$, Desmones JC, Otteni $J C$, Scherpereel $P$. Morbidity and mortality associated with anaesthesia - French survey: Preliminary results. In: Mortality in Anaesthesia, MD Vickers and JN Lunn eds. Springer-Verlag, Berlin 1982; 26-38.

12 Davies $J M$, Strunin L. Anesthesia in 1984: How safe is it? Can Med Assoc J 1984; 131: 437-41.

\section{Résumé}

Ce papier expose les résultats de neuf ans d'étude d'un programme de suivie post-anesthésique dans un grand hôpital universitaire $(N=112,721$ anesthésies). Pour les périodes de 1975-78 et 1979-83 plus de patients sérieusement malades (classe ASA plus élevés) ont été traités. La pratique anesthésique a aussi changé avec un accroissement dans l'utilisation d'une anesthésie balançée (l'utilisation de plusieurs drogues) la diminution dans l'utilisation de l'halothane et une augmentation dans l'utilisation des moniteurs physiologiques. Les complications anesthésiques non léthales pour les périodes per-opératoire, en salle de réveil et en période post-opératoire étaient rares. Cependant on a observé un accroissement dans le taux de complications rapporté d travers le temps. Pour la période de 1975-78, une complication per-opératoire a été rapportée pour 7.6 pour cent des cas. De 1979-83, ce pourcentage augmenta à 10.6 pour cent. Pour les complications survenant à la salle de réveil on observa un accroissement de 5.9 pour cent en 1979-83 à partir de 3.1 pour cent en 1975-78. Dans la deuxième période étudiée le risque d' avoir des complications post-opératoire reliées à l'anesthésie était de 9.4 pour cent avec 0.45 pour cent de risque d'avoir une morbidité significative. Ceci représente un accroissement par rapport à la première période de 8.9 et 0.40 pour cent respectivement. On conclut que l'expérience anesthésique même si elle est associée avec un taux de mortalité bas dans les dernières années reste pour le moins encore associee avec une morbidité significative. Il est hypothétique actuellement de penser que ceci peut être le reflet de l'état pré-opératoire du patient, de la pratique anesthésique ou tout autre variable indéfinie associée avec une expérience chiruricale. 